REVISTA CHILENA DE LITERATURA

Diciembre 2016, Número 94, 233-256

\title{
LITERATURA CHILENA EN DIGITAL: MAPAS, ESTÉTICAS Y CONCEPTUALIZACIONES ${ }^{1}$
}

\author{
Carolina Gainza C. \\ Universidad Diego Portales \\ carolina.gainza@udp.cl
}

\section{RESUMEN / ABSTRACT}

En el presente artículo se busca analizar una experiencia estética vinculada a lo digital, que tiene como principales componentes la posibilidad de interactuar, participar y manipular las obras creadas en este formato. Con tal fin, se presentará un mapa de la literatura digital en Chile, para luego profundizar en el análisis de dos aspectos que permiten caracterizar una estética de lo digital: la hipertextualidad y el hackeo cultural. A partir de estos elementos y tomando en cuenta que la literatura digital es aquella creada para ser leída en la pantalla de un dispositivo electrónico, se analizan el poema $A$ veces cubierto por las aguas de Carlos Cociña y el poemario Clickable poem@s de Luis Correa-Díaz. Estas obras nos permiten preguntarnos por el estatus de la literatura y la poesía en la era digital, vinculadas a una experiencia estética que pone énfasis en la intervención y el deseo de participación.

Palabras clave: literatura digital en Chile, poesía digital, estética digital, hipertexto.

This article examines an aesthetic experience associated with the digital, which is characterized by the ability of the reader to interact, participate, and manipulate literary works created in this format. First, a map of Chilean digital literature will be presented and then two aspects will be analyzed which allow a description of an aesthetic of the digital: hypertextuality and cultural hacking. As a result of this analysis, and considering that digital literature is that which is created to be read on the screen of an electronic device, two poems will be investigated: A veces cubierto por las aguas by Carlos Cociña and Clickable poem@s by Luis Correa-Díaz. These texts allow us to think about the status of literature and poetry in the digital era, linked with an aesthetic experience which emphasizes intervention and the wish to participate.

KEYWORDS: Digital literature in Chile, digital poetry, digital aesthetics, hypertext.

1 Este artículo expone resultados y análisis realizados en el marco del proyecto Fondecyt de Iniciación №11140247, "Cultura digital en Chile: literatura, música y cine". 
Preguntarse por las posibilidades creativas de las tecnologías digitales podría parecer una trivialidad en nuestros días. Lo digital se encuentra en el corazón de la producción cultural, dado que actualmente toda producción artística pasa por algún tipo de procedimiento vinculado a estas tecnologías: desde la producción cinematográfica a la musical, desde la escritura y edición de libros hasta la exhibición de obras artísticas, como por ejemplo los museos online ${ }^{2}$. La materialidad digital transforma los procesos de producción, circulación y recepción de las obras artísticas, donde estas mismas categorías se vuelven porosas y sus límites se vuelven difusos.

Sin embargo, la naturalización de los usos de lo digital en los procesos creativos, por el aumento en la disponibilidad y experiencia que tenemos en relación al uso, lectura y manipulación de obras construidas en base a procedimientos digitales, no necesariamente implica una correlación con nuestra comprensión del fenómeno en sus efectos, lógicas de funcionamiento, experiencias, estéticas y modos de creación. En efecto, muchas de las obras digitales no son aceptadas dentro de lo que entendemos por literatura, cine, música o arte. De esta forma, las experimentaciones con lo digital en la literatura plantean preguntas como: ¿es literatura una obra que integra lenguaje escrito, imágenes en movimiento y elementos interactivos? ¿Qué pasa con una obra que no tiene principio ni fin? ¿Una obra que cambia cada vez que la leemos o que debe ser intervenida por el lector puede ser definida como un poema?

Lo interesante de estas preguntas es que nos vuelcan al quehacer literario y a una revisión de lo que entendemos por obra, autor, lector, géneros literarios, escritura y otros elementos que definen la práctica literaria. Por otra parte, en las nuevas formas de hacer literatura que surgen con lo digital, quedan en evidencia los límites de las disciplinas. La afirmación de Octavio Paz realizada en su texto de 1967, en que se refería a la visibilidad que había adquirido la oralidad por sobre la palabra escrita en las vanguardias, puede ser aplicada a la transformación actual que experimenta la literatura:

La técnica cambia a la poesía y la cambiará más y más. No podía ser de otro modo: su intervención afecta tanto a la transmisión y recepción de poemas como a los métodos para componerlos. Pero esos cambios, por más profundos que nos parezcan, no la desnaturalizan. Al contrario,

$2 \quad$ En efecto, Lev Manovich señala: "Hoy nos encontramos en medio de una nueva revolución mediática, que supone el desplazamiento de toda la cultura hacia formas de producción, distribución y comunicación mediatizadas por el ordenador" (64). 
la devuelven a su origen, a lo que fue al principio: palabra hablada, compartida por un grupo (5).

En el presente artículo nos interesa discutir dos elementos que nos permiten describir una estética de lo digital presente en la literatura creada para ser leída en este soporte. Consideramos que esta discusión es fundamental para comprender la experiencia que genera la creación y lectura en el medio digital. El contexto del análisis es la literatura digital chilena, particularmente la poesía digital desarrollada por dos autores: Carlos Cociña y Luis Correa-Díaz. Con este objetivo se presentará en primer lugar una muestra de literatura digital chilena, para luego desarrollar el análisis de las obras mencionadas a partir de dos elementos que configuran una experiencia estética propia de este formato: el hipertexto y el hackeo cultural.

\section{MAPA DE LA LITERATURA DIGITAL EN CHILE: NAVEGAR EN TEXTUALIDADES HIPERTEXTUALES}

Antes de comenzar a describir la presencia de literaturas digitales en Chile, es importante abordar la definición de literatura digital. La literatura digital refiere a un tipo de escritura y textualidad creada para ser leída en la pantalla de un dispositivo electrónico ${ }^{3}$. En este sentido, cuando nos referimos a ella no estamos hablando de textos impresos digitalizados para ser leídos en formato digital, lo cual generalmente obedece al formato e-book. Si bien en los e-books podemos observar un proceso de traducción al lenguaje digital de ceros y unos, la estructura del texto y la forma de escritura no se modifica. Por el contrario, la literatura digital apunta a una experimentación con el lenguaje en este formato, una escritura en código que se despliega en forma de textos escritos, imágenes, animaciones y sonidos, que, en la gran

\footnotetext{
En este sentido, adherimos a la definición provista por Katherine Hayles, quien señala que la literatura nacida para el medio digital es "a first generation digital object created in a computer and (usually) meant to be read in a computer" (3). Sin embargo, se trata de un concepto en discusión, tal como lo propone Luis Correa-Díaz en su revisión de las definiciones que existen en torno a la literatura digital, y particularmente a la poesía digital. Recomiendo revisar la discusión del concepto que realiza este autor en su introducción al libro Poesía y poéticas digitales / electrónicas / tecnos / New-Media en América Latina.
} 
mayoría de los casos, son dispuestos de formas no lineales ${ }^{4}$. Por tanto, el mapa que presentamos acá tiene un doble objetivo: mostrar algunas de las obras de literatura digital existentes en Chile y, al mismo tiempo, aprender a navegar poéticas y narrativas cuyos senderos se bifurcan, como en el famoso cuento de Borges.

En este sentido, el énfasis está puesto en el cambio en la materialidad de la escritura: la escritura se vuelve performática porque la literatura digital es expresión de la ejecución de un código, el cual es activado por un sujeto, frente al cual se despliegan una serie de textualidades que interactúan con él/ ella. Para comprender este cambio en la materialidad de la escritura, resulta útil recurrir al análisis que realiza Boris Groys sobre la imagen digital:

(...) una imagen digital, para ser vista, no ha de ser meramente exhibida sino escenificada, performada. Aquí es cuando la imagen comienza a funcionar de forma análoga a una pieza musical -La partitura en sí siendo la parte silenciosa. Para que la música pueda resonar, ha de ser interpretada. En consecuencia, se puede decir que la digitalización convierte a las artes visuales en un arte escénico (16).

Este argumento podría extenderse a la literatura digital, en la cual es necesaria una acción de parte del lector que afecte la materialidad de la obra, momento en que se despliega un acto performativo del código para que el contenido de la obra sea proyectada ante los ojos del lector. De esta experimentación, que no es una mera "remediación" (Bolter y Grusin 1999) del formato anterior, surgen estructuras narrativas y poéticas diversas, muchas de las cuales son imposibles de presentar en el formato impreso sin que pierdan por completo su significación y su sentido. Se trata de poéticas en red que solo pueden ser experimentadas en el formato digital, lo que hace que el lenguaje que las constituye apunte a experiencias de lectura que escapan a las formas

Para una discusión sobre el lenguaje digital y las especificidades creativas que éste presenta para la literatura digital recomiendo revisar Ergodic Literature de Espen Aarseth y The Making of E-Poetries de Loss Pequeño Glazier. Más vinculado a la discusión que desarrollaremos sobre el hackeo cultural, como producto de la manipulación característica del lenguaje digital, recomiendo revisar Uncreative Writing de Kenneth Goldsmith y Tactical Media de Rita Raley. 
de recepción vinculadas a la materialidad impresa, con su predominio del lenguaje escrito ${ }^{5}$.

Hablamos de obras que requieren de una participación del lector que sobrepasa el nivel de la interpretación y significación del texto ${ }^{6}$. El lector hace suyo el texto digital no solo porque lo re-significa, sino que también porque lo afecta materialmente, al disponer sus propios caminos de lectura o al activar las imágenes, videos y sonidos que confieren sentido a lo leído. Esta lecturajuego consiste en activar los códigos del texto y en armar el rompecabezas que el autor pone en manos del lector. Sin embargo, el rompecabezas tiene múltiples formas de armarse, donde, y tal como ocurre en las redes, los autores arriesgan perder el control sobre sus creaciones.

En el contexto chileno, la literatura digital constituye un campo de creación y experimentación donde podemos encontrar trabajos tanto en narrativa como en poesía. Algunos obedecen a la definición que hemos entregado de literatura digital. Otros podrían ser definidos como proyectos transmedia, es decir, que utilizan plataformas digitales como extensiones de la publicación impresa. En algunos casos, el objetivo es generar un contacto más directo con los lectores, como en las novelas de Jorge Baradit. En otros, se parte de creaciones audiovisuales y performáticas para derivar en textos escritos, como ocurre en Hembros de Eugenia Prado?

$5 \quad$ En este punto es importante señalar que algunas de las expresiones de la cultura digital ya existían en el formato impreso. El hipertexto por ejemplo, y refiriéndonos a uno de los ejemplos más típicos en este contexto de discusión, se había ensayado en obras como "Rayuela" de Julio Cortázar. También las enciclopedias serían una forma de hipertexto. Otro ejemplo característico de prácticas realizadas en lo impreso que se trasladan y potencian en lo digital son algunas experimentaciones de las vanguardias, como el "cadáver exquisito". El fanfic es otro ejemplo ya existente en el formato impreso, vinculado a la re-escritura realizada por fans de sus literaturas, series o películas favoritas. Sin embargo, en este análisis enfatizamos que el formato digital potencia lo que en el formato impreso se realizaba de forma minoritaria y marginal, justamente por las características estáticas de lo impreso. Por otra parte, esas prácticas ya experimentadas en el formato impreso adquieren características diferentes en el digital, que corresponde a lo que exploramos en este artículo.

Como señala Adolfo Sánchez, en estas obras "se da un tipo de intervención del receptor que afecta no sólo a la interpretación, dotación de sentido o valoración de la obra, sino también a su aspecto sensible, material" (21). Sin embargo, además de esto, se trata de obras "relacionales" que construyen espacios de sociabilidad a partir de una experiencia estética interactiva (Bourriaud 2009).

Actualmente Eugenia Prado se encuentra en proceso de publicar Asedios, novela que deriva de la novela-instalación del año 2004. Como la define su autora, Asedios es "un texto de ficción siempre en proceso" (S/P). 
A continuación presentamos un cuadro de obras de autores chilenos que experimentan con lo digital, tanto en narrativa como en poesía. No se trata de una recopilación definitiva, sino que más bien se trata de un mapa en construcción, donde las obras se conectan y nos permiten navegar en un terreno, hasta ahora, poco conocido en la literatura nacional.

\begin{tabular}{l|l}
\hline Narrativa & Poesía \\
\hline $\begin{array}{l}\text { Pentagonal- Carlos Labbé } \\
\text { (2001) }\end{array}$ & $\begin{array}{l}\text { Orquesta de poetas- Fernando Pérez } \\
\text { Villalón, Felipe Cussen, Pablo Fante, } \\
\text { Federico Eisner. (2011) } \\
\text { (Poesía sonora- digital) }\end{array}$ \\
\hline $\begin{array}{l}\text { Synco (2008), Policía del Karma (2011) } \\
\text { y Lluscuma (2013). Jorge Baradit } \\
\text { (Novelas impresas que se acompañan } \\
\text { de recursos online, tales como páginas } \\
\text { web, booktrailers en youtube y páginas } \\
\text { de facebook, entre otras.) }\end{array}$ & $\begin{array}{l}\text { (poesía transmedia) } \\
\text { (2016) }\end{array}$ \\
\hline $\begin{array}{l}\text { Hembros “Asedios a lo posthumano"- } \\
\text { Eugenia Prado (Novela instalación- CD- } \\
\text { youtube) } \\
\text { (2004) }\end{array}$ & $\begin{array}{l}\text { Poemámez. (poesía visual- digital) } \\
\text { (2004) }\end{array}$ \\
\hline $\begin{array}{l}\text { Mi pololo volvió de Antuco- Ignacio } \\
\text { Nieto (2005) } \\
\text { "Mpropiación de la obra de Olia Lialina } \\
\text { War” (1996)) }\end{array}$ & $\begin{array}{l}\text { Poesía cero. Carlos Cociña } \\
\text { (2003) }\end{array}$ \\
\hline $\begin{array}{l}\text { Cuentiwts- Fabián Saez (2011-) } \\
\text { (Publicación impresa de una selección } \\
\text { de 24 tweets en 2014) }\end{array}$ & $\begin{array}{l}\text { Feedback. Martín Gubbins (2014) } \\
\text { digitales) }\end{array}$ \\
\hline $\begin{array}{l}\text { Video narrativas. René Orellana } \\
\text { (2010) }\end{array}$ & $\begin{array}{l}\text { Poema del Terremoto. Gregorio } \\
\text { Fontén(2010) }\end{array}$ \\
\hline
\end{tabular}

La búsqueda de nuevos lenguajes, experiencias estéticas y las posibilidades de interacción con otros lenguajes, como el de la imagen o el sonido, son algunas de las características que podemos observar en estas obras. Sin embargo, considero que son dos las que más se adecuan a las posibilidades 
que abre la materialidad digital: la red, como estructura que permite generar una experiencia estética vinculada a la posibilidad de un texto abierto y azaroso, tanto en sus posibilidades de construcción, sus lenguajes y su lectura; y la posibilidad de intervenir las obras producto del carácter manipulable del lenguaje digital. Respecto a esto último, definiremos como hackeo cultural la potencialidad que tienen estas obras de ser intervenidas por lo lectores, posibilidad dada por las características del lenguaje digital.

Las obras que presentamos en el cuadro manifiestan estas características en distintos niveles. Por ejemplo, Pentagonal: Incluidos tú y yo (2001) de Carlos Labbé y algunos poemas incluidos en Poesía cero de Carlos Cociña (2003), como A veces cubierto por las aguas (2003), se construyen como hipertextos, donde el azar juega un rol central en la construcción de sentido así como en la experiencia estética del lector. Por otra parte, se trata de narrativas y poéticas que transmiten la sensación de un texto sin fin y potencialmente extensible por el lector. En efecto, esta parece ser una de las características más llamativas de lo digital: la posibilidad de generar un texto sin fin con el potencial de una intervención material del lector en el texto, es decir, más allá del trabajo de significación. Esta intervención ocurre tanto en el acto de armar el propio puzle poético o de lectura, como en la generación de una experiencia de participación basada en la activación de un deseo, que proviene de la posibilidad de disponer del texto de diversas maneras.

En la obra de René Orellana también encontramos el imaginario de un texto infinito. En un video-relato como Manuel y Rosario (2006), de su colección de video-narrativas, nos encontramos con una propuesta estética vinculada al libro sin fin, donde se presenta una historia circular que alude al ciclo solsticial. En una versión más cerrada que la apertura textual que representa el hipertexto digital, el video plantea la posibilidad de un relato que no acaba, sino que se reinventa con cada vuelta al sol. En este sentido, en el texto de Orellana observamos otra forma de representar la estructura textual abierta del hipertexto, incorporando elementos audiovisuales que adquieren incluso una importancia mayor que el texto escrito.

La importancia de la visualidad y lo sonoro en lo digital se aprecia principalmente en los hipermedia. George Landow (2006) define el hipertexto como un texto compuesto por bloques de texto interconectados a través de enlaces electrónicos (3). Siguiendo esta definición, el autor señala que un hipermedia corresponde a la misma estructura, solo que en vez de presenciar la interconexión de textos escritos, asistimos a una obra que entrelaza 
diversas textualidades, que pueden pertenecer a variados medios $(2006)^{8}$. En las obras hipermediales, el sentido se construye a partir de la exploración de los diversos recursos que componen una poética o un relato. Si bien en Pentagonal de Carlos Labbé encontramos algunos recursos visuales, su estructura principal está compuesta por bloques de texto interconectados, al igual que $A$ veces cubierto por las aguas de Carlos Cociña. Mi pololo volvió de Antuco (2005) -obra que se suma a las diversas apropiaciones de la obra de la artista rusa Olia Lialina, My Boyfriend Came Back From the $\underline{W a r}$ (1996) y que demuestra justamente el carácter manipulable del lenguaje digital-, se acerca más a lo que sería un texto hipermedial, en cuanto el relato es acompañado con imágenes que evocan el escenario de la tormenta en que ocurrió la tragedia de Antuco en $2005^{9}$. La obra adquiere significado a partir de la activación de textualidades escritas y visuales que se entrelazan en la construcción del sentido del texto.

Sin embargo, la hipertextualidad hace referencia también a otro fenómeno, donde los enlaces no solo ocurren dentro de la obra, sino que la obra, tanto narrativa como poética, se construye a través de enlaces a otros medios. En este caso, hablamos de transmedialidad ${ }^{10}$, es decir, a obras que se construyen como redes que enlazan distintos medios y que salen del contexto medial de la obra, con lo que, al mismo tiempo, abren mayores espacios para la participación de los lectores/usuarios. En este sentido, el texto se construye a partir de enlaces a páginas web, imágenes que circulan en Internet y videos en youtube; o también pueden referir a una novela impresa que se conecta con elementos existentes en la red Internet. En este sentido, por transmedialidad entendemos una poética o relato construido a partir de las conexiones entre

8 Acá podríamos agregar el análisis de Lev Manovich (2005), quien señala que "un objeto de los nuevos medios consta de partes independientes, cada una de las cuales se compone de otras más pequeñas y así sucesivamente (...)" (76). Esto se puede aplicar a una definición de hipertexto e hipermedia donde un hipertexto está compuesto de enlaces, bloques de texto, frases, palabras, caracteres, donde cada uno obedece a un código diferente; y un hipermedia está compuesto de múltiples recursos (texto, imagen, sonidos, videos, etc.). En ambos, cada elemento conserva su singularidad e identidad.

La tragedia de Antuco hace referencia a la muerte de 44 soldados conscriptos y un sargento en una marcha durante una ventisca con $-35^{\circ}$ de temperatura en mayo de 2005 , en el volcán Antuco en la Región del Biobío. Los soldados estaban haciendo su servicio militar y estaban al mando del mayor Patricio Cereceda y el comandante Luis Pineda.

10 Para el tema de las narrativas transmedia, sugiero consultar Convergence Culture de Henry Jenkins, y Narrativas Transmedia de Carlos A. Scolari. 
elementos existentes en distintos formatos, escrito, sonoro, visual, animado, entre otros, así como en distintos medios: video, impreso, digital, entre otros.

La diferencia entonces con un hipermedia se encuentra en la relación entre los elementos que conforman la red de textualidades, y si esta red ocurre mayoritariamente dentro de la obra o en una composición que es una suma de diversos medios. Sin embargo, en ambos casos, los elementos componentes de la red tienen una existencia propia, que, por sí mismos, tienen un sentido $\mathrm{y}$ una singularidad, y que adquieren diversos significados en la conexión que establecen con los otros elementos de la red. En este sentido, la composición se asemeja a la figura del rizoma descrito por Deleuze y Guattari (2009). Dentro de las obras transmediales, encontramos los trabajos de Jorge Baradit, Eugenia Prado y Luis Correa-Díaz.

Cuentwits de Fabián Sáez obedece a otra forma de creación literaria en la red y que utiliza el formato de twitter para construir microrrelatos. Se trata de una narrativa que se arma a partir de posteos en twitter, formato que permite textos de un máximo de 140 caracteres. De esta forma, cada tweet es un relato en sí mismo, y al mismo tiempo, es posible construir un relato en la conexión de cada uno de los tweet. En la obra de Sáez, cada tweet mantiene su singularidad, es decir, posee una identidad en cuanto relato singular, y, al mismo tiempo, contribuye a la construcción de un relato mayor que deviene una red de relatos. Acá, el concepto de narrativa rizomática también funciona, en cuanto los post poseen una significación tanto en sus 140 caracteres como en la red que el lector construye al conectar cada uno de ellos.

Por otra parte, twitter como plataforma interactiva permite que los lectores participen comentando los tweets y retwitteándolos. Incluso, sería posible que un lector tome un tweet y construya otro relato a partir del mismo. De esta forma, en las redes sociales se abre la posibilidad de generar redes creativas, con un potencial de generar comunidades que hacen difusas las divisiones entre autores y creadores. En este contexto, el hipertexto existe no solo como estructura literaria, sino que también acarrea un potencial de convertirse en una red de relaciones sociales creativas ${ }^{11}$.

11 Para profundizar en el tema de las narrativas y poéticas en Twitter, con énfasis en el contexto latinoamericano, sugiero revisar el trabajo, recientemente publicado, de Sarah Lowman y Luis Correa-Díaz, La tuit(er)-ficción en el (ciber)espacio literario hispanoamericano (2015). 
Poema del terremoto de Gregorio Fontén es un poema interactivo que utiliza el lenguaje HTML. Está construido en base a declaraciones de personas después del terremoto ocurrido en Chile en el año 2010. La página principal nos advierte que se trata de un poema que contiene diez páginas, las que se van superponiendo a medida que hacemos click en letras y frases, y que la navegación puede ser difícil. En efecto, el lector debe tratar de acceder a las distintas partes del poema presionando en las letras de la palabra terremoto para que éstas se muevan simulando un movimiento telúrico. Así, las letras se mueven de un lado a otro, de adelante hacia atrás, giran, suben y bajan. Junto con reproducir el efecto de movimiento que genera un terremoto, acompañado de las declaraciones de quienes lo experimentaron, el poema busca remecer al lector en sus expectativas creadas en el formato anterior, y lo invita a explorar en un terreno, el digital, que efectivamente está siempre en movimiento.

La Orquesta de Poetas y la poesía sonora de Martín Gubbins constituyen un caso especial. En el caso de los primeros, su performance creativa, que mezcla poesía y música, ocurre en vivo ${ }^{12}$, frente a un público que participa de una experiencia estética en que la literatura se vuelve performance musical. La poesía se lee, se actúa, se escucha, pero además, es intervenida por procedimientos digitales en tiempo real. Las voces de quienes leen son distorsionadas y se mezclan con sus actuales voces. Finalmente, queda la materialidad de la palabra, un lenguaje vaciado de significado, pero que al mismo tiempo ofrece la posibilidad de ser re-significado a partir de las intervenciones digitales y performáticas realizadas por quienes actúan sobre el lenguaje poético. Se trata, como señala su declaración de principios, de invadir el lenguaje y la literatura.

En la Orquesta de Poetas, se observa una experimentación con la materialidad del lenguaje, pero más allá de esto, con la posibilidad de traspasar las barreras de las disciplinas. Música y literatura son intervenidas por el lenguaje digital, que las hace manipulables y permite su distorsión y transformación. Las obras de Carlos Cociña, Oswald de Andrade y Arthur Rimbaud, entre otros, son intervenidas en tiempo real, frente a un público que experimenta la transformación de los lenguajes conocidos. En este sentido, la potencialidad que tienen las tecnologías digitales de ser utilizadas para 
hackear las estructuras y lenguajes existentes son posibles de apreciar en las performances realizadas por la Orquesta de Poetas.

Un trabajo similar, en cuanto cruza disciplinas como la música y la poesía, y además experimenta con la materialidad del lenguaje, lo encontramos en la poesía sonora de Martín Gubbins. El autor entiende la creación como un trabajo colaborativo, por lo cual en sus trabajos generalmente participan otros poetas y músicos. Esto se plasma en el título de su disco de poesía sonora publicado en 2014, Feedback, disponible en el sitio web Bandcamp ${ }^{13}$ y en el que participan, entre otros, Felipe Cussen y Martín Bakero. Lo digital, si bien no es central en su proceso creativo, si juega un rol importante como facilitador de ciertos procedimientos que el autor incorpora en sus poemas sonoros, por ejemplo, para mezclar sonidos en vivo, distorsionar voces, generar efectos de repetición, entre otros. Lo anterior afecta no solo la experiencia creativa, sino que también la experiencia del receptor.

En este "mapa en construcción" de obras podemos observar que el lenguaje digital potencia diversas formas de experimentación, en las cuales, sin embargo, se observan dos constantes. La primera, vinculada a la experiencia hipertextual consistente en una red de textualidades, donde el lenguaje digital permite que los elementos textuales puedan ser dispuestos de diversas formas en el proceso de significación, tanto por el lector, autor, o quizás sea mejor llamarlos operadores. Esta cualidad está íntimamente ligada a la posibilidad de intervención que presentan las obras digitales, de hackeo, de afectar materialmente las obras, y también de trabajar colaborativamente. La intervención material a veces ocurre porque algunas obras digitales están hechas para ser intervenidas. En otros casos, quizás la mayoría, lo digital presenta la potencialidad de activar un deseo en el operador de extender las redes textuales e intervenir el lenguaje, al hacerlo consciente del carácter manipulable del lenguaje digital ${ }^{14}$.

13 Bandcamp es una plataforma de música en línea que ha sido especialmente utilizada por artistas emergentes como plataforma de lanzamiento y distribución.

14 Un ejemplo donde este deseo de intervención se hace patente es en el fanfiction, fenómeno en que los lectores crean nuevos relatos a partir de sus novelas favoritas. Hasta el momento whatpad y fanficiton.net son los sitios más populares. 


\section{POÉTICAS EXTENDIDAS}

En esta parte del análisis nos enfocaremos en dos obras de poesía chilena en virtud de los elementos que configuran una experiencia estética vinculada a lo digital. Ya hemos identificado y definido estos elementos: la hipertextualidad que se construye como una red de conexiones entre distintos elementos, tanto dentro como hacia afuera de la obra, y la posibilidad de manipular el lenguaje digital, que hemos llamado hackeo cultural. Ambos apuntan a una experiencia relacionada con el acto de afectar materialmente las obras, lo cual potencia la activación de un deseo de participación en el operador. Las características intrínsecas del lenguaje de códigos, propio de lo digital ${ }^{15}$, ofrece la posibilidad de intervenir las obras, modificarlas y manipularlas.

\section{A VeCES CUbIerto POR LAS AGUAS De CARlos CociÑa}

Carlos Cociña ${ }^{16}$ nos presenta en su proyecto Poesía Cero el poema hipertextual $A$ veces cubierto por las aguas, el cual fue concebido para ser leído en la pantalla de un computador. Este poema además fue utilizado por la Orquesta de Poetas, quienes, junto a la lectura aleatoria de los poemas por parte de Cociña, introducen elementos sonoros que generan una atmósfera dramática ${ }^{17}$.

La web de Poesía Cero presenta un diseño minimalista, un fondo blanco con los títulos de los poemas en letras de color negro y algunos títulos en color verde. La lista funciona como el índice de un poemario que se activa al clickear en los títulos. Al entrar al poema $A$ veces cubierto por las aguas nos encontramos con una descripción técnica y una advertencia:

15

Lev Manovich explica que esta característica de manipulación obedece a la reproductibilidad numérica que posee el lenguaje digital. El autor señala que las imágenes en movimiento, sonidos, formas, espacios y textos son todos computables, compuestos de datos informáticos. Este nuevo estatuto de los medios permite que los nuevos medios sean más manipulables, lo que deriva en otras prácticas culturales de creación. Esto, según el autor, tiene que ver con la forma en que la capa informática y la capa cultural se influyen mutuamente “en su organización, en sus géneros emergentes y en sus contenidos" (93).

16 Carlos Cociña es un poeta chileno nacido en Concepción. Ha publicado alrededor de ocho poemarios, entre ellos Aguas servidas (1981), Espacios de líquido en tierra (1999), A veces cubierto por las aguas (2003) y plagio del afecto (2010). Es uno de los pocos poetas chilenos que ha experimentado con el formato digital en poesía.

17 Esta lectura-performance está disponible en la página de la Orquesta de Poetas: https://www.youtube.com/watch?v=KD3sSLWU4Oo 
IMPORTANTE: Motor de búsqueda aleatorio en el cual el usuario accede a uno de los 39 poemas cada vez. Al desear ver otro poema, se despliega nuevamente al azar uno de los 39 , pudiendo repetirse un poema visto anteriormente. Existe la opción de regresar, pero la elección de otro poema, será siempre aleatorio ( $A$ veces, web).

Se trata de una advertencia al lector que pareciera querer indicar que no se trata de un poema convencional. En este sentido, y como es casi habitual en las obras digitales, se nos ofrece un manual de uso. Como en los videojuegos, es importante que los lectores conozcan el funcionamiento de la obra, para poder moverse en un territorio poético irreconocible. Se trata de advertir al lector que se enfrentará a una experiencia desconocida, que al mismo tiempo significa un aprendizaje, como si fueran instrucciones para aprender a leer o, por el contrario, apaciguar la incertidumbre que genera una poética en la que desconocemos el destino, que no tiene principio ni final. En este sentido, el lector debe abandonarse a la exploración del poema, tanto en sus significados como en su materialidad.

Figura 1. Captura de imagen online de $A$ veces cubierto por las aguas

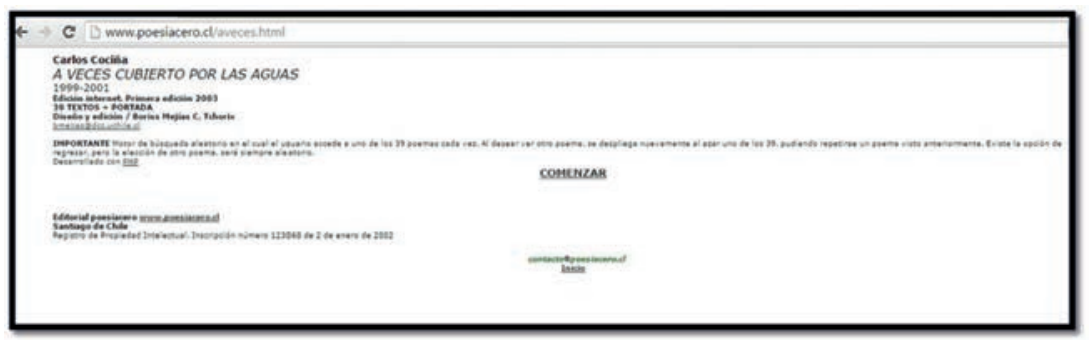

$\mathrm{Al}$ entrar en el poema, se nos presenta un bloque de texto que en los extremos superiores de la página contiene dos botones para ser operados por el lector, "inicio" y "otro". El diseño es bastante intuitivo, lo que facilita al lector la tarea de explorar el poema. El significado lo construye cada lector, en cada click del mouse en el botón "otro". El botón "inicio" nos lleva de vuelta al listado de poemas de la página. Sin embargo, nuestro camino de lectura será diferente porque el algoritmo poético tiene otro camino de lectura aguardando por nosotros. En este sentido, la lectura del poema nunca será la misma.

De esta forma, se invita al lector a avanzar y navegar en las aguas azarosas del poema, y no se le permite retroceder para observar el camino trazado. Se trata de un avanzar con los ojos vendados, un entregarse al poema. También 
es una invitación al juego en un texto que se ramifica a medida que se avanza en la lectura. En este sentido, la experiencia que tiene el lector/operador se relaciona con el acto de la navegación a través de las opciones azarosas que nos presenta el texto.

Figura 2. Captura de pantalla, comienzo aleatorio de la lectura del poema $A$ veces cubierto por las aguas.

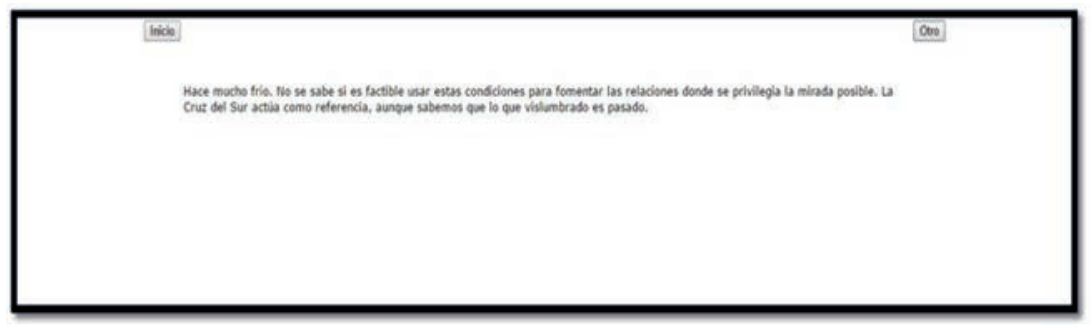

Cociña señala en una entrevista realizada por Felipe Cussen (2010): “Cuando tú navegas (en cualquier plano), está el azar, por eso pedí a un amigo ingeniero que creara una maquinita de azar" (7). Esta maquinita de azar es la que permite enlazar el texto escrito con el lenguaje computacional, donde se requiere una acción de parte del lector para "activar" el texto y que este se despliegue. En este sentido, el lenguaje de códigos es el que permite una poética en constante movimiento.

A veces cubierto por las aguas invita al lector a combinar, a jugar con los textos poéticos, tal como el autor lo hizo en "Plagio del afecto" (2009) con diversos textos científicos ${ }^{18}$ : "lo que digo es que los elementos son finitos, pero las combinaciones tienden al infinito" (Cociña, Entrevista 8). En el poema nos encontramos que el lenguaje de códigos se esconde a nuestros ojos, como señala Groys (2012), e interpela al lector a activar una poética que se presenta múltiple en sus caminos de lectura, enfrentándolo a la incertidumbre de lo infinito y la imposibilidad de una coherencia establecida a priori. El lector es convocado a seguir el camino que le ofrece el azar, un llamado a

18 En Plagio del afecto, Cociña interviene textos científicos. En la web Poesía cero, Plagio del afecto está compuesto por 52 "afectos" y 53 en el libro impreso (2009). En esta versión impresa, el último "afecto" corresponde a una página en blanco, en lo que pareciera ser una invitación a que el lector continué el proceso de afectar textos. En ambas obras, los poemas corresponden a textos plagiados, intervenidos y comentados por el autor. 
abandonarse a la poesía. En este sentido, su capacidad de acción sobre el poema es mínima, no se le permite elegir más allá de avanzar o volver a leer otro poema. El lenguaje de códigos es el que dispone los bloques de texto que se desplegarán ante sus ojos.

Sin embargo, a pesar de que lo anterior podría sonar restrictivo, representa todo lo contrario. Para que los caminos textuales se activen y se desplieguen ante un lector, es necesario que éste los manipule, los navegue e interactúe con ellos. El lector de textos electrónicos debe aprender a jugar con los elementos que le presenta el texto, debe ejecutar sus códigos. En este sentido, mientras el lector sigue el camino trazado por el azar, se activa un deseo de intervención, de manipulación. El poema que se presenta ante los ojos del lector no solo invita a la construcción de significado, sino que nos hace conscientes de una materialidad que nos convoca a activar enlaces que nos presentan caminos de lectura. Al respecto, uno de los bloques de texto que podemos encontrar en nuestra lectura azarosa señala:

En los kilómetros de mar, de pronto está todo por construirse y, aunque acabo de regresar de la marea, nada existe de lo que creí soñaba. Por lo mismo, una gran isla vista desde esta posición, es una isla en esta posición. Es éste el caso de dormir como un acto activo, donde se oye claro desde alguna de las tantas orillas que se vislumbran en la imaginación de los sentidos ( $A$ veces, web).

En este poema está todo por construirse, una y otra vez. Sus caminos son combinables, en una experiencia que permite al lector percibir la potencialidad del lenguaje digital, en su multiplicidad y la posibilidad de su manipulación. De esta forma, la performatividad del texto posibilita la activación de un deseo de intervención que permite que el texto incluso pueda ser extendido más allá del poema. La hipertextualidad digital refiere precisamente a una estructura azarosa que nos invita a navegar en su diversidad de textualidades, y al mismo tiempo, construir una red de significados y posibilidades creativas. Estas posibilidades creativas están contenidas en el lenguaje digital, que no solo posibilita esta estructura, sino que al mismo tiempo, nos permite manipularla.

En este sentido, la hipertextualidad como elemento de la estética digital no solo tiene que ver con la existencia de múltiples caminos de lectura, sino que más allá de eso, expresa el tipo de relaciones sociales que establecemos en esta época: interacciones extendidas y multiplicadas por las características materiales de las nuevas tecnologías y las redes sociales. Lo hipertextual no solamente estructura los textos digitales, donde el texto se extiende, se 
recicla información, se enlaza con otras obras, etc., sino que además, estas redes configuran una estética particular de lo digital relacionada con formas de colaboración, participación e interacción entre las obras, la máquina, los autores y los lectores.

\section{CLICKABLE POEM@S DE LUIS CORREA-DíAZ}

Los clickablepoem@sde Luis Correa-Díaz ${ }^{19}$ son poemas que reflexionan sobre la condición del sujeto en la era digital y que exploran las posibilidades de los enlaces electrónicos. Se trata de 24 poemas que se encuentran dispersos en diversas páginas y revistas en la web ${ }^{20}$ y que recientemente han sido reunidos en un libro publicado en julio de $2016^{21}$. El "vínculo" o el "link" es el tema central, pero no solo porque los lectores son invitados a operar estos enlaces, sino que también porque finalmente estos enlaces dan cuenta de la forma en que nos relacionamos hoy en día: a un click de distancia. No solo los poemas están concebidos en estructuras hipertextuales, sino que lo humano en la era digital se estructura en torno a la imagen de la red. Y como tal, las redes siempre poseen un potencial de expansión, que actualmente el lenguaje digital materializa a través de los enlaces que se multiplican hasta el infinito.

Las relaciones humanas constituyen uno de los temas centrales en los poemas de Correa-Díaz. El amor, la amistad, la soledad, la nostalgia que estas relaciones provocan son temáticas presentes en sus versos. Sin embargo, el contexto de esas relaciones ocurre en la actualidad en estrecha vinculación con las redes sociales, sus lenguajes y mecanismos. En vez de generar extrañeza, Correa-Díaz plasma en sus Clickable poem@s una cotidianeidad $\mathrm{y}$ un realismo en que las redes sociales y las tecnologías digitales son parte de nuestro lenguaje y de la manera de relacionarnos. En efecto, Eleonora Finkelstein señala que una característica fundamental de los poemas de

Luis Correa-Díaz es un poeta chileno, trabaja actualmente como profesor de literatura latinoamericana en la University of Georgia-USA. Ha publicado numerosos textos académicos, poemas y ensayos.

20 Estos poemas han sido publicados en diferentes espacios, como la Revista Laboratorio, Letras S5, Periódico de poesía de la UNAM y en la Revista Casa de las Iguanas, entre otros.

$21 \quad$ Clickable poem@s fue publicado en formato impreso. Los poemas son acompañados de códigos QR que permiten acceder a los poemas digitales en cualquier dispositivo electrónico. Todos los poemas de Luis Correa-Díaz citados en el artículo corresponden a esta colección. 
Correa-Díaz se relaciona con que lo hipertextual aparece como una cuestión natural, ya asimilada por los sujetos de nuestro tiempo:

Clickable poem@s es un libro plenamente contemporáneo: amplificado, enchufado, multicultural y multifocal. Todos adjetivos que asumen, con una autopercibida y en consecuencia retransmitida sinceridad, y sin aspirar más que a la comprobación primaria, lo que significa ser "hoy" en el mundo. Pero, por si fuera poco, se trata de un enamorado en este mundo. Sí, el amor, same old thing, pero aquí y ahora, donde somos capaces de estar en varios lugares al mismo tiempo, en vivo o viajando a través de esos atajos entre realidades que llamamos "links" (1)

Lo hipertextual aparece en los poemas como estructura que permite extender las redes hasta el infinito, que cala hasta lo más profundo de la subjetividad contemporánea. Las relaciones se desenvuelven entre chats, emails, conversaciones por skype, por facebook y otras redes sociales, donde adquieren otras lógicas. La presencia virtual del otro/a está en el "from" de un email, en los emoticones de los mensajes instantáneos, en todos aquellos enlaces invisibles que nos conectan con el otro, en los cuales nos hacemos partícipes de una existencia virtual que afecta nuestras formas de percepción y permiten relaciones que ocurren en diversos tiempos y espacios ${ }^{22}$. El poema $i ð$ expresa estas relaciones que hoy establecemos, mediadas por la tecnología digital:

desde que vi esa luz en tus ojos hago cosas curiosas, como, por ejemplo, y me río: acariciar tu breve nombre en el from del e-mail, con el cursor voy y vengo sobre él, oigo en cada letra, quiero creer, tu respiración

22 Esta mediación tecnológica de las relaciones humanas está presente en la concepción posthumanista del sujeto, que refiere a una subjetividad "relacional" que no se reduce a la relación entre humanos, sino que se establece en las redes de relaciones que construimos entre agentes humanos y no humanos, que incluye la tecnología. En este sentido, más que como prótesis de lo humano, las tecnologías son entendidas como agentes actantes (Latour 2007). En efecto, Žižek plantea en su libro Órganos sin cuerpo (2006) que, en vez de preocuparnos por la pérdida de "humanidad" en manos de los artefactos tecnológicos "pensantes", deberíamos pensar en cómo esos objetos desafían esa noción de subjetividad asociada a la primacía de lo humano. 
y siento que alguien en ti nos habla

en su old norse para decir quedo, como un feliz augurio, Deir ganga

saman á hálum ísi, en falla eigi

http://www.youtube.com/watch?v=CMWkqwrmuXI

(Correa-Díaz s/n)

La hipertextualidad cala en la experiencia del sujeto. Esta experiencia de vida está íntimamente ligada a una experiencia estética y creativa que podemos observar en las poéticas digitales, y que corresponde al tema que nos interesa ahondar en esta discusión. En primer lugar, el autor se apropia de los elementos que circulan en las redes sociales y los hace partícipes del poema: enlaces a canciones, videos y otros textos. En este sentido, el poeta es un hacker, que se apropia e integra en su proceso creativo los recursos disponibles de forma libre en la red. Su experiencia de vida está marcada por la hipertextualidad -y la clickabilidad-, en la cual la experiencia actual consiste en un constante proceso de creación de enlaces en medio de la navegación por Internet y las redes sociales:

así ha quedado este hombre enamorado que fui: una especie de cyberphantom en esta multitasking ópera tecno nuestra, seguro de que la usura de los años, a diferencia de quien dijera esto, le ha dejado por todo los ojos sanos; frente al espejo digital, con una acordada pretendida extrañeza, asiste al espectáculo mudo de sí mismo: un viejo prematuro que lee blogs, websites, revistas y newspapers online, post y photo sharing en my space of facebook (all kind of social networks para acompañarse el alma, en tentación cayendo a veces de entregarla, de puro aburrido existir, alas pasajero, a los tv broadcasts on the Internet, favoritos a la fecha los live grids de mogulus), qué decir de la cantidad diaria e indigesta de e-mails de toda procedencia, borrados casi en el acto (hábito que hoy equivale a algo parecido a una sesión de higiene personal, incluida la conciencia), aunque nunca olvida revisar escrupulosamente 
los del junk folder por si allí hubiese ido

a parar el que espera por siempre;

(monimenta autoterapéuticas/n)

Por otra parte, los hipervínculos presentes en los poemas nos permiten experimentar una cercanía con el proceso creativo, lo cual modifica la forma en que se produce la literatura. Unas poéticas que se extienden a partir de los enlaces provistos por el autor, que poseen el potencial de seguir siendo extendidos por los lectores/operadores.

y llegados a este punto es que vacilo, e-lector/a, y no sé con cuál dejarte (to set you free from this poem) si con ésta o con la de The Who, la que le sirvió de hipotexto - cosa que así será for generations to come-, ... como se dice, entonces: ante la duda, abstenerse, elije tú mismo/a: http://www.youtube.com/watch?v=RhY5k_5WPCA http://www.youtube.com/watch? $\mathrm{v}=\mathrm{zqfFrCUrEbY}$ (iDA - en un i-mode slightly tántrico $\mathrm{s} / \mathrm{n}$ )

Los enlaces interpelan al lector, en una especie de llamado a "completar" el poema. Así se abre la posibilidad de una extensión del proceso creativo más allá de la palabra escrita, y donde, al mismo tiempo, se extiende la práctica de lectura. Tanto la vida como la literatura constituyen una experiencia hipertextual en la poesía de Luis Correa-Díaz, en la cual el poeta hacker invita a los lectores a recorrer las redes digitales, en busca de conexiones que salen del poema. Por otra parte, el acto de creación consiste en apropiarse de estos enlaces, de reflexionar sobre ellos, tanto por parte del autor como del lector. En este caso, el lector es llamado a apropiarse también de la cultura digital.

De esta manera, los sujetos son provocados por el poema para afectar materialmente su estructura, extenderlo y experimentar la hipervinculación que el hablante poético expresa en su poesía como experiencia vital. Son instados a hackear la literatura, su materialidad, sus poéticas, a incluir nuevos elementos y apropiarse de las redes. Pensamos que es quizás aquí donde se encuentra el potencial político de la literatura digital y de la experiencia estética que promueve. 


\section{ESTÉTICAS DIGITALES: EL PLACER DEL TEXTO Y LA PARTICIPACIÓN}

Del análisis que hemos presentado se puede inferir que existe una tendencia en las creaciones presentes en la literatura digital -cuestión que hemos mirado particularmente en dos expresiones creativas en el contexto chilenoa entender el proceso creativo como un proceso inmanente, como una red creativa que se plasma en la figura del hipertexto. El mapa que presentamos al comienzo busca funcionar como una cartografía hipertextual provisoria, que nos permita navegar las diversas formas de creación que ocurren en el contexto de la era digital en nuestro país.

Lo anterior deriva en una experiencia estética digital que tiene su acento en la posibilidad de participar en el proceso creativo, ya sea desde la interacción en que vamos produciendo conexiones entre diversas textualidades, como en el caso de la poesía de Cociña, o en experiencias que nos llevan fuera del poema y que abren la puerta para explorar otros enlaces creativos, como en los poemas de Luis Correa-Díaz. Lo anterior nos habla de una experiencia del sujeto en la era digital en que el placer del texto está marcado por la posibilidad que abre lo digital de afectar materialmente la literatura, desde hacer click en un enlace, extenderlos, crear redes de lectura e, incluso, la posibilidad y el potencial del hipertexto digital de permitir la reescritura y reelaboración de lo ya creado por otros.

Cuando hablamos de estética digital buscamos marcar una diferencia con otros conceptos similares, como la estética relacional de Nicolás Bourriaud (2009) o la estética de la emergencia de Reinaldo Laddaga (2010). En consecuencia, buscamos enfatizar la existencia de una materialidad, la digital, que provoca los cambios descritos, la cual es apropiada y resignificada en las prácticas literarias que aquí hemos mencionado y analizado. Si bien existen similitudes entre lo que proponemos y las conceptualizaciones mencionadas, sobre todo en cuanto a la posibilidad de generación de comunidades creativas, el acento de la experiencia estética digital que analizamos se encuentra en la existencia de un lenguaje digital que al ser apropiado por los sujetos, potencia el acto de afectar materialmente las obras.

Ponemos énfasis en la materialidad, en referencia tanto al lenguaje digital como a la estructura hipertextual que resulta de ese lenguaje, porque consideramos que es central para comprender una experiencia estética vinculada a lo digital y las implicancias políticas que surgen de las prácticas ligadas a ésta. La materialidad digital posibilita la existencia de flujos narrativos, 
poéticos y de información que pueden pasar de un dispositivo a otro, o que permiten manipular las diversas textualidades. En este sentido, existe un proceso de retroalimentación entre la literatura y el medio (lenguaje) en que se expresa, proceso en el cual se desarrollan diversas prácticas creativas. Toda tecnología ha tenido algún impacto en la literatura, algunas en mayor medida que otras (el libro, la imprenta, la máquina de escribir, el cine, la fotografía, entre otras). Al respecto, Loss Pequeño Glazier señala:

Electronic writing is not simply the e-quivalent of paper writing, because writing that is electronic has different properties than writing that is on paper. Does a message carved into granite differ from one scratched into sand? One might be inclined to be slightly more taciturn in the former medium. The difference is in physical and material properties. The most interesting of these are not static properties (i.e., how many lines there are in the text or how many bytes it occupies) but properties that relate to the malleability of the electronic text. These are properties that inject the unpredictable into the work (...) (84).

Its only constant is that it is likely to change for each instance in which it is viewed. It is a textual site with a momentum that can shift in any direction (85).

En este sentido, las políticas que se derivan de la experiencia estética que describimos se relacionan con la posibilidad de una manipulación material del texto, experiencia que proviene de la interactividad y posibilidades de participación que abre el lenguaje digital. El lector es interpelado tanto a significar la obra como a descifrar su estructura. El autor, como en varios de los ejemplos que vimos en el mapa presentado, también interviene y manipula imágenes, textos y otros recursos disponibles en la web.

El libro permite una experiencia en la que el sujeto interpreta y resignifica las propuestas autorales. Esta es la forma en que nos apropiamos de los relatos, los poemas, las poéticas y las narrativas y las sacamos de la propiedad del autor. No obstante, en la era digital ocurre algo diferente. Más allá de apropiarnos de los textos a través de la interpretación, podemos hacerlos nuestros en su materialidad, donde incluso la diferencia entre autor y lector comienza a hacerse borrosa. Esto ocurre porque la estructura del hipertexto se potencia en el lenguaje digital, como señala Douglas: "If the book is a highly refined example of a primitive technology, hypertext is a primate example of a highly refined technology, a technology still at the icebox stage" (15). 
En este sentido, el lenguaje digital permite manipular los textos, mezclarlos, remixearlos, reescribirlos, afectarlos, lo cual permite situar las prácticas de la literatura digital en el conflicto actual vinculado con la propiedad intelectual. Es por esto que el hackeo es parte de la experiencia estética que provoca la literatura digital, y se lleva a cabo a partir de las conexiones y manipulaciones que realizamos a partir de las redes hipertextuales.

De esta forma, el hipertexto digital abre la puerta a una forma diferente de concebir el proceso creativo, y a una experiencia en que el lector/operador puede experimentar ser parte de ese proceso. Muchas veces ni siquiera necesita del permiso del autor, sino que es posible apropiase de los textos, intervenirlos y transformarlos porque la composición del lenguaje digital lo facilita. En este sentido, se trata de un asalto a la propiedad material de los textos. Es aquí donde aparece la figura del hackeo cultural, la cual hace referencia a la posibilidad de afectar la literatura, donde, como señalamos en el análisis, el placer del texto está en crear, participare interactuar, tanto con el texto, como con la máquina, el autor y otros lectores. En este sentido, la literatura digital se aleja de la experiencia individual y contemplativa de la obra, y se vincula a una experiencia activa que requiere de un acto no trivial del sujeto, como expresa el análisis de E. Aarseth: "The cybertext reader is a player, a gambler; the cybertext is a game- world or a world-game; it is possible to explore, get lost, and discover secret paths in these texts, not metaphorically, but through the topological structures of the textual machinery" (4).

La estructura del hipertexto representa la posibilidad latente que existe en la cultura digital de extender la producción cultural, hacerla más participativa, donde es posible transformarse en creador, utilizando software y otras herramientas creativas disponibles. En la cultura digital todo es potencialmente hackeable. No es que esto no haya podido realizarse con anterioridad, sino que más bien el lenguaje digital potencia prácticas que antes se realizaban con dificultad en el formato impreso. A esta experiencia y forma de percepción que se vincula a una forma de apreciar el texto y su poética, en sus posibilidades de participación e interacción, es a lo que hemos llamado estética digital, la cual, como hemos analizado, se vincula a una condición textual específica, en que la literatura se vuelve programable y manipulable. 


\section{BIBLIOGRAFÍA}

Aarseth, Espen. Cybertext: Perspectives on Ergodic Literature. Baltimore: The John Hopkins UP, 1997. Impreso.

Bolter, David y Richard Grusin. Remediation. Understanding New Media. Massachusetts: MIT Press, 1999. Impreso

Bourriaud, Nicolás. Relational Aesthetics. France: Les presses du réel, 2009. Impreso

Cociña, Carlos. "A veces cubierto por las aguas". Poesía Cero, 2003. Web, mayo 2016. <http:// www.poesiacero.cl/aveces.html>.

"Desde el tímpano hacia adentro" Entrevista realizada por Felipe Cussen. Revista Chilena de Literatura. Sección Miscelánea/ Noviembre 2010.

Plagio del afecto.Santiago: Ediciones Tácitas, 2009. Impreso

Plagio del afecto. Poesía Cero. Libro en proceso 2003- 2005. Web, mayo 2016. $<\mathrm{http}: / /$ www.poesiacero.cl/plagiodelafecto.html $>$.

Correa Díaz, Luis.Clickable poem@s.Santiago: RIL Ediciones, 2016. Impreso.

Correa-Díaz, Luis y Scott Weintraub. Eds. Poesía y poéticas digitales / electrónicas / tecnos / New-Media en América Latina. Editorial Universidad Central, Bogotá, Colombia, 2016. Libro electrónico, Open Access. <http://www.ucentral.edu.co/editorial/catalogo/ poesia-poeticas-digitales>

Correa-Díaz, Luis y Sarah Lowman. "La tuit(er)-ficción en el (ciber)espacio literario hispanoamericano". Dossier "Paperless Text: Digital Storytelling in Latin America and Spain (1983-2013)".Letras Hispanas 11 (2015).<http://www.modlang.txstate.edu/letrashispanas/ previousvolumes/vol11.html>

Deleuze, Gilles y Felix Guattari. A Thousand Plateaus. Capitalism and Schizophrenia. Minneapolis: University of Minnesota Press, 2009. Impreso

Douglas, Jane Yellowlees. The end of books -or books without end?Ann Arbor: Univ. of Michigan Press, 2000. Impreso

Finkelstein, Eleonora. “Clickable poem@s o el flâneur contemporáneo: poesía amplificada, enchufada, multifocal”. Prólogo. Correa-Díaz, Luis. Clickable poem@s. Santiago: RIL Ediciones, 2016. Páginas 1-5. Impreso.

Goldsmith, Kenneth. Uncreative Writing. New York: Columbia University Press, 2011. Impreso.

Groys, Boris. "De la imagen al archivo de imagen $-\mathrm{Y}$ de vuelta: el arte en la era de la digitalización". Castillo, Alejandra y Cristián Gómez- Moya. Arte, archivo y tecnología. Santiago: Ediciones Universidad Finis Terrae, 2012. Impreso.

Hayles, Katherine. Electronic Literature. Indiana: University of Notre Dame Press, 2008. Impreso.

Jenkins, Henry. Convergence Culture: Where Old and New Media Collide. New York: New York University Press, 2008. Impreso.

Labbé, Carlos. Pentagonal. 2001. Web, mayo 2016, <http://www.ucm.es/info/especulo/ hipertul/pentagonal/> 
Laddaga, Reinaldo. Estética de la emergencia. Buenos Aires: Adriana Hidalgo editores, 2010. Impreso.

Landow, George. Hipertext 3.0. Critical Theory and New media in an Era of Globalization. Baltimore: The John Hopkins University Press, 2006.

Latour, Bruno. Reassembling the Social. An introduction to actor-network theory. New York: Oxford University Press, 2007.

Loss Pequeño Glazier. Digital Poetics: the Making of E-Poetries. Alabama: The University of Alabama Press, 2002. Impreso.

Manovich, Lev. El lenguaje de los nuevos medios de comunicación. Barcelona: Paidós, 2005. Impreso.

Nieto, Ignacio. Mi pololo volvió de Antuco. 2005. Web, junio 2016. <http://myboyfriend camebackfromth.ewar.ru/antuco/>

Orellana, René. Manuel y Rosario. 2006. Web, mayo 2016.<http://www.artistasplasticoschilenos. cl/reneorellana/09_ManuelyRosario.html>

Orquesta de Poetas. Declaración de principios. Santiago: Cumshot, 2014. Web, mayo 2016. $<$ http://www.portaldisc.com/gratis.php?id=11893>

Paz, Octavio. "La nueva analogía: poesía y tecnología". El signo y el garabato. México: Seix Barral, 1992.

Prado, Eugenia. Hembros: Asedios a lo Post-humano. Revista Laboratorio de Escrituras, (publicación en Agosto 2016). Web<http://www.laboratoriodeescrituras.cl/>

Raley, Rita. Tactical Media. Minneapolis: University of Minnesota Press, 2009. Impreso.

Saéz, Fabián. Cuentwits. Twitter, Junio $2016<$ https://twitter.com/cuentwits>

Scolari, Carlos A. Narrativas Transmedia. Cuando todos los medios cuentan. Barcelona: Deusto, 2013. Impreso.

Sánchez Vásquez, Adolfo. "De la estética de la recepción a la estética de la participación". Marchán, Simón. Ed. Real/virtual en la estética y la teoría de las artes. Barcelona: Editorial Paidós, 2006.

Žižek, Slavoj. Órganos sin cuerpo. Sobre Deleuze y sus consecuencias. Valencia: Pre-Textos, 2006. 